\title{
Biflavonoids and other Phenolics from Caesalpinia pyramidalis (Fabaceae)
}

\author{
Marcus V. Bahia ${ }^{a}$, Jamile B. dos Santos ${ }^{a}$, Juceni P. David ${ }^{b}$ and Jorge M. David ${ }^{*, a}$ \\ ${ }^{a}$ Instituto de Química and ${ }^{b}$ Faculdade de Farmácia, Universidade Federal da Bahia, Campus de Ondina, \\ 40170-290 Salvador-BA, Brazil
}

\begin{abstract}
O reestudo do extrato clorofórmico das folhas de Caesalpinia pyramidalis (Caesalpinioidea, Fabaceae) forneceu, além do novo biflavonóide denominado caesalflavona, podocarpusflavona A, agathisflavona, apigenina, kaempferol, sitosterol e lupeol. Por outro lado, a partir do extrato clorofórmico do caule foram obtidos 4, 4'-diidroxi-2'-metoxi-chalcona, (-)-siringaresinol e galato de metila. Não foram encontrados biflavonóides nesta parte da planta. Até o presente, $C$. pyramidalis é a primeira espécie do gênero que contém biflavonóides. As estruturas das substâncias foram estabelecidas através da análise dos seus dados espectrométricos utilizandose técnicas de EM, IV, UV, RMN 1D e 2D.
\end{abstract}

The chloroform extract of the leaves of Caesalpinia pyramidalis (Caesalpinioidea, Fabaceae) yielded the new biflavonoid named caesalflavone, as well as podocarpusflavone A, agathisflavone, apigenin and kaempferol. The chloroform extract of the trunk wood gave 4,4'-dihydroxy-2'methoxychalcone, (-)-syringaresinol, and methyl gallate. Biflavonoids were not found in trunk wood. Until now, $C$. pyramidalis is the first species in the genus to present biflavonoids. The structural elucidation of the isolated compounds and their derivatives were based on MS, IR, UV, 1D and 2D NMR spectral analyses.

Keywords: Caesalpinia pyramidalis, Fabaceae, biflavonoids, flavonoids

\section{Introduction}

The genus Caesalpinia (Caesalpinioideae, Fabaceae), comprised of tropical or subtropical trees or shrubs, contains more than 150 species worldwide. ${ }^{1}$ Native Brazilian species such as Caesalpinia echinata "paubrasil" had important economic value in the early colonial period of Brazil. ${ }^{2}$ Previous studies of species of this genus report remarkable biological activities for its species such as antimicrobial, ${ }^{3}$ antidiabetic ${ }^{4}$ (C. bonducella), antimalarial $^{5}$ (C. volkensii and C. pluviosa), and antiinflammatory ${ }^{6}$ activities (C. sappan and $C$. ferrea). Caesalpinia pyramidalis Tul is an endemic tree of northeastern region and one of the predominant species in the "caatinga" vegetation. In Bahia State, it is popularly known as "catingueiro" or "pau-de-rato", and its leaves are employed in traditional medicine as diuretic, dyspeptic, digestive, and antipyretic. ${ }^{7}$

In a previous work ${ }^{8}$ on organic extracts from $C$. pyramidalis leaves, the isolation of phenylpropanoids, lupeol, sitosterol, and a biflavone known as aghatisflavone

* e-mail: jmdavid@ufba.br were described. The present work describes the phytochemical reexamination of the chloroform extract from leaves and trunk wood of $C$. pyramidalis. A new biflavonoid named caesalflavone (1) was isolated, along with the known compounds podocarpusflavona A (2), agathisflavone (3), apigenin, and kaempferol. From the chloroform extract trunk wood were obtained the known compounds 4,4'-dihydroxy-2'-methoxychalcone (4), syringaresinol (5), and methyl gallate.

\section{Results and Discussion}

The protonated molecular ion $[\mathrm{M}+\mathrm{H}]^{+}$observed at $\mathrm{m} / \mathrm{z} 541$ in low resolution ESIMS combined with proton and carbon counts by ${ }^{1} \mathrm{H}$ NMR and ${ }^{13} \mathrm{C}$ NMR spectra (including DEPT) pointed to the molecular formula $\mathrm{C}_{30} \mathrm{H}_{20} \mathrm{O}_{10}$, suggesting a biflavonoid nature for compound $\mathbf{1}$.

NMR data is in agreement with mass spectrum and showed that the biflavonoid is made up of flavanone and flavone units (Table 1). The flavone unit was identified by the signals at $\delta 182.9, \delta 164.5$, and $\delta 103.3$ relative to an $\alpha, \beta$-unsaturated carbonyl group. On the other hand, the flavanone unit was recognized by its characteristic 
Table 1. ${ }^{13} \mathrm{C}$ NMR data of biflavonoids $\mathbf{1}, 2$ and $\mathbf{3}\left[\left(\mathrm{CD}_{3}\right)_{2} \mathrm{CO}, \delta\right.$ (ppm) $]$

\begin{tabular}{|c|c|c|c|c|c|c|}
\hline \multirow[t]{2}{*}{$\mathrm{C}$} & \multicolumn{2}{|c|}{1} & \multicolumn{2}{|c|}{2} & \multicolumn{2}{|c|}{3} \\
\hline & I & II & I & II & I & II \\
\hline 2 & 164.5 & 79.5 & 165.0 & 164.7 & 163.9 & 163.8 \\
\hline 3 & 103.3 & 42.8 & 103.2 & 103.1 & 103.2 & 102.7 \\
\hline 4 & 182.9 & 197.2 & 183.3 & 183.1 & 182.2 & 181.9 \\
\hline 5 & 165.2 & 163.1 & 161.5 & 162.8 & 159.7 & 160.7 \\
\hline 6 & 96.4 & 99.5 & 99.7 & 99.7 & 103.6 & 99.2 \\
\hline 7 & 159.4 & 166.1 & 166.7 & 165.7 & 163.7 & 163.5 \\
\hline 8 & 95.7 & 94.7 & 94.8 & 105.3 & 94.1 & 99.9 \\
\hline 9 & 157.6 & 161.7 & 158.4 & 156.7 & 157.1 & 155.1 \\
\hline 10 & 106.4 & 104.5 & 103.9 & 104.1 & 103.8 & 104.1 \\
\hline $1^{\prime}$ & 122.2 & 130.7 & 121.6 & 121.6 & 121.5 & 121.7 \\
\hline $2^{\prime}$ & 128.9 & 118.8 & 128.6 & 128.8 & 128.5 & 128.2 \\
\hline $3^{\prime}$ & 116.6 & 129.1 & 121.3 & 115.2 & 116.3 & 116.2 \\
\hline $4^{\prime}$ & 162.0 & 159.1 & 159.4 & 162.3 & 161.3 & 161.1 \\
\hline $5^{\prime}$ & 116.6 & 114.4 & 117.7 & 115.2 & 116.3 & 116.2 \\
\hline $6^{\prime}$ & 128.9 & 115.8 & 133.1 & 128.8 & 128.6 & 128.2 \\
\hline $\mathrm{OCH}_{3}$ & - & - & - & 55.7 & - & - \\
\hline
\end{tabular}

${ }^{13} \mathrm{C}$ signals, which were attributed to a carbonyl group as well as to the $\mathrm{C}-2$ and oxybenzylic carbon of ring $\mathrm{C}$. However, the biflavonoid structure of caesalflavone (1) was corroborated mainly through the presence of two nonhydrogenated carbon resonances at $\delta 96.4$ and $\delta 129.1$, suggesting the linkage of ring $\mathrm{C}$ of the flavanone unit and ring A of the flavone unit. Thus, the linkage at C-6 of the flavone unit was established due to the presence of methine carbon signals at $\delta 95.7, \delta 116.6$, and $\delta 128.9$ as well as hydrogen signals at $\delta 5.94, \delta 7.02$, and $\delta 7.94$. The C-6 flavone linkage was also suggested by the shielded peak of the methine carbon C-8 $(\delta$ 95.7) and through comparison with data in literature for agathisflavone, ${ }^{8}$ amentoflavone, ${ }^{9}$ and binaringenin..$^{10}$ Additionally, the C-3' linkage of the flavanone unit was proposed through ${ }^{13} \mathrm{C}$ NMR, which confirmed the substitution pattern of rings $\mathrm{A}$ and $\mathrm{C}$ (Table 1).

The ${ }^{1} \mathrm{H}$ NMR spectrum of $\mathbf{1}$ also corroborated to propose the biflavonoid structure and the linkage between the flavanone and flavone units. Thus, this spectrum showed single hydroxyl bounded group signals at $\delta 12.16$ and $\delta 13.01$, which were recognized after the addition of $\mathrm{D}_{2} \mathrm{O}$. Besides, the double doublet signals at $\delta 5.39$, 3.19 , and 2.72 as well as the single signal at $\delta 6.63$ were characteristic of $\mathrm{H}-2, \mathrm{H}-3 \alpha$ and $\mathrm{H}-3 \beta$, and $\mathrm{H}-3$ of ring $\mathrm{C}$ of flavanone and flavone moieties, respectively. ${ }^{11}$ This spectrum also showed characteristic signals (Table 2) that allowed determining the substitution pattern of rings $\mathrm{A}$ and $\mathrm{B}$ observed for each flavonoid unit. Thus, the single signal at $\delta 5.94$ suggested a pentasubstituted ring A while the meta coupling constant $(J=1.9 \mathrm{~Hz})$ observed for the signals at $\delta 6.54$ and 6.25 suggested the presence of a further tetrasubstituted ring A. The existence of a
Table 2. ${ }^{1} \mathrm{H}$ NMR data of caesalflavone (1) $\left[\left(\mathrm{CD}_{3}\right)_{2} \mathrm{CO}, \delta(\mathrm{ppm}), J=\mathrm{Hz}\right]$

\begin{tabular}{ccc}
\hline & & $\mathbf{1}$ \\
$\mathrm{H}$ & $\mathrm{I}$ & $\mathrm{II}$ \\
\hline 2 & - & $5.39(\mathrm{dd}, 12.6,3.0)$ \\
3 & $6.63(\mathrm{~s})$ & - \\
$3 \mathrm{a}$ & - & $3.19(\mathrm{dd}, 14.0,12.6)$ \\
$3 \mathrm{~b}$ & - & $2.72(\mathrm{dd}, 14.0,3.0)$ \\
6 & - & $6.25(\mathrm{~d}, 1.9)$ \\
$8^{\prime}$ & $5.94(\mathrm{~s})$ & $6.54(\mathrm{~d}, 1.9)$ \\
$2^{\prime}$ & $7.94(\mathrm{~d}, 8.7)$ & $6.84-6.86(\mathrm{~m})$ \\
$3^{\prime}$ & $7.02(\mathrm{~d}, 8.7)$ & - \\
$5^{\prime}$ & $7.02(\mathrm{~d}, 8.7)$ & $7.02(\mathrm{dd}, 2.0,8.1)$ \\
$6^{\prime}$ & $7.94(\mathrm{~d}, 8.7)$ & $6.84-6.86(\mathrm{~m})$ \\
$\mathrm{OH}^{\prime}$ & 12.16 & 13.01 \\
\hline
\end{tabular}

1,4-dissubstituted ring B was shown by characteristic doublets $(\delta 7.02$ and $\delta 7.94)$ relative to two hydrogens each and to an additional trisubstituted ring $B$ due to the presence of three hydrogen signals (Table 2).

However, the structure was only confirmed after analyses of ${ }^{1} \mathrm{H}-{ }^{1} \mathrm{HCOSY}$, HMQC, and HMBC bidimensional spectra. The HMQC spectrum was elucidative because it was possible to verify the correlations of two hydrogen signals and two carbon resonances each. Thus, the correlations observed between the peaks displayed at $\delta 7.02$ and $\delta 116.6$ and $\delta 114.4$ as well as $\delta 6.86$ and $\delta 115.8$ and $\delta 118.8$ permitted to identify $\mathrm{C}-5^{\prime} / \mathrm{H}-5^{\prime}$ of units I and II and C$2^{\prime} / \mathrm{H}-2^{\prime \prime}$ and $\mathrm{C}-6^{\prime} / \mathrm{H}-6^{\prime}$ of unit II. The main correlations observed at ${ }^{1} \mathrm{H}-{ }^{1} \mathrm{H}$ COSY confirmed the flavanone unit and its 1,4-substitution. However, the analysis of HMBC spectrum data for the linkage between the flavonoid units was conclusive. The spectrum showed a hydrogen correlation for ring B of flavanone and C-1' II and C2II. On the other hand, the bonded hydroxyl ( $\delta$ 12.16) 

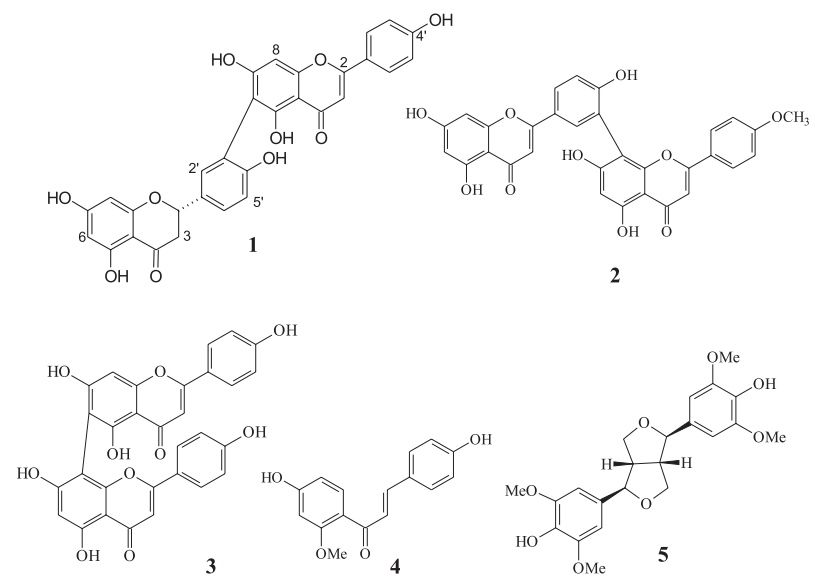

Figure 1. Biflavonoids and other phenolics isolated from Caesalpinia pyramidalis.

at C-5 of unit I showed correlation with the nonhydrogenated carbon C-6 ( $\delta$ 96.4) of unity I. The correlation of $\mathrm{H}-8$ and $\mathrm{C}-10$ of unity I was conclusive to identify this unit as being the flavone linked with C3 ' of the flavanone unit II (Figure 2). To date, there are no reports in literature regarding compound $\mathbf{1}$.

Podocarpusflavone A (2) was identified by MS and NMR data analysis. Unequivocal assignments of ${ }^{13} \mathrm{C}$ NMR signals (Table 1) were obtained by HMQC and HMBC experiments. Comparison with literature data ${ }^{9}$ permitted to re-assign some peaks. Other slight differences in resonances observed between compound 2 and literature data were attributed to the solvent employed. Agathisflavone and other biflavone derivatives have been tested as topoisomerase inhibitors. ${ }^{12}$ It is noteworthy that $C$. pyramidalis is the first specimen of the genus to present biflavonoids, which are still rare for Leguminosae.

Compound 4 (4,4'-dihydroxy-2'-methoxy-chalcone) was identified by NMR analysis. The position of the methoxyl group was established by UV spectral analysis with the $\mathrm{AlCl}_{3}$ reagent shift. The absence of bathochromic effect permitted to localize the methoxyl group in the C-2'. This chalcone was previously found in C. sappan $^{13}$ and ${ }^{13} \mathrm{C}$ NMR data has been recorded for the first time.

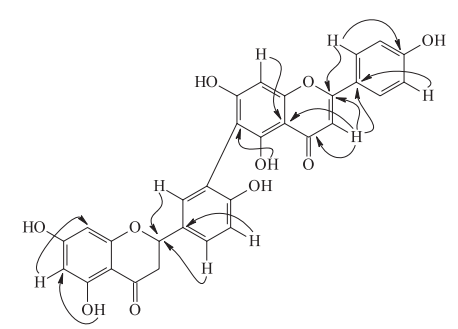

Figure 2. Selected HMBC correlations of Caesalflavona (1).

\section{Experimental}

\section{General procedures}

${ }^{1} \mathrm{H}(300 \mathrm{MHz}) ;{ }^{13} \mathrm{CNMR}$ and DEPT $(75 \mathrm{MHz}) ;{ }^{1} \mathrm{H}-{ }^{1} \mathrm{H}$ COSY and ${ }^{1} \mathrm{H}^{-13} \mathrm{C}$ COSY experiments were carried out in a Varian mod. Gemini 2000. HMQC and HMBC were run in a Bruker DRX 500: chemical shifts were recorded in $\delta$ (ppm) from the solvent peak relative to TMS; ESIMS (Micromass mod. Quattro); UV spectra were carried out in a Varian CARY I equipment. Infrared spectra were recorded in a JASCO mod. Valor II spectrophotometer. Optical rotations were measured in a Carl Zeiss polarimeter.

Botanical material of $C$. pyramidalis was collected at Valente, Bahia State, a region where "caatinga" vegetation is prevalent. Species identification was kindly provided by Prof. Letícia Scardino (Instituto de Biologia, Universidade Federal da Bahia) and a voucher is deposited at Herbarium Alexandre Leal Costa da Universidade Federal da Bahia under number 0240291.

\section{Isolation of constituents}

Dry trunk wood $(5.6 \mathrm{Kg})$ and leaves $(680.0 \mathrm{~g})$ were individually extracted with $\mathrm{MeOH}$. Separately, the crude extracts obtained were immediately partitioned with hexane/MeOH: $\mathrm{H}_{2} \mathrm{O}$ (9:1), $\mathrm{CHCl}_{3} / \mathrm{MeOH}: \mathrm{H}_{2} \mathrm{O}$ (6:4), and after the evaporation of $\mathrm{MeOH}$ under vacuum the aqueous phase obtained were partitioned with $\mathrm{EtOAc} / \mathrm{H}_{2} \mathrm{O}$. The hexane partition $(7.5 \mathrm{~g})$ of trunk wood, following fractionation by column chromatography (CC) using silica gel as adsorbent and eluted with hexane/EtOAc 85:15 and $7: 3$, respectively, furnished a mixture of sitosterol and stigmasterol $(86.0 \mathrm{mg}$ ), and lupeol (49.4 mg). The chloroform partition $(23.9 \mathrm{~g})$ of the trunk wood was fractionated by $\mathrm{CC}$ on silica gel and mixtures of $\mathrm{CHCl}_{3} /$ EtOAc. The fraction eluted with $\mathrm{CHCl}_{3} / \mathrm{EtOAc}(8: 2)$, followed by an additional purification step by $\mathrm{CC}$ with $\mathrm{Si}$ gel, with $\mathrm{CHCl}_{3} / \mathrm{MeOH}$ as solvent, yielded 4,4'-dihydroxy2'-methoxy-chalcone $(4,5.3 \mathrm{mg})$ and (-)-syringaresinol $(\mathbf{5}, 13.0 \mathrm{mg})$. Compound 4 was eluted with $\mathrm{CHCl}_{3} / \mathrm{MeOH}$ 95:5 and $\mathbf{5}$ with $\mathrm{CHCl}_{3} / \mathrm{MeOH}$ 9:1. The fraction eluted with $\mathrm{CHCl}_{3} / \mathrm{EtOAc}$ (7:3), followed by flash $\mathrm{CC}$ using $\mathrm{Si}$ gel $60 \mathrm{H}$ as adsorbent and $\mathrm{CHCl}_{3} / \mathrm{MeOH}$ (9:1) as eluent, yielded methyl gallate.

The chloroform extract $(19.7 \mathrm{~g})$ of the leaves was CC on silica gel eluted with mixtures of $\mathrm{CHCl}_{3} / \mathrm{EtOAc}$ in increasing polarity. Thus, the fraction eluted with $\mathrm{CHCl}_{3} /$ EtOAc (9:1) furnished lupeol and sitosterol ${ }^{14}(268.8 \mathrm{mg})$, and the fraction eluted with $\mathrm{CHCl}_{3} / \mathrm{EtOAc}(8: 2)$ yielded 
podocarpusflavone A (2, $8.0 \mathrm{mg})$. The fraction eluted with $\mathrm{CHCl}_{3} /$ EtOAc (6:4) followed by gel permeation in Sephadex LH-20 using $\mathrm{CHCl}_{3} / \mathrm{MeOH}(2: 3)$ as eluent furnished pure agathisflavone $(\mathbf{3}, 38.9 \mathrm{mg})$. The fraction eluted with $\mathrm{CHCl}_{3} / \mathrm{EtOAc}(1: 1)$, followed by further silica gel CC with $\mathrm{CHCl}_{3} / \mathrm{MeOH}$ (9:1), yielded caesalflavone $(1,7.0 \mathrm{mg})$ and, $\mathrm{CHCl}_{3} / \mathrm{MeOH}$ (85:15) furnished apigenin (5.0 mg), and kaempferol ${ }^{11}(8.0 \mathrm{mg})$.

Caesalflavone (1). Pale yellow power; $\mathrm{mp} 360^{\circ} \mathrm{C}$ with decomposition; $[\alpha]_{\mathrm{D}}-6.0^{\circ}(\mathrm{MeOH}, c$ 0.007); ESIMS $(\mathrm{m} / \mathrm{z}): 541\left(\mathrm{M}+\mathrm{H}, \mathrm{C}_{30} \mathrm{H}_{20} \mathrm{O}_{10}\right) ;{ }^{13} \mathrm{C} \mathrm{NMR}\left(\mathrm{CD}_{3}\right)_{2} \mathrm{CO}$ : Table $1 ;{ }^{1} \mathrm{H}$ NMR $\left(\mathrm{CD}_{3}\right)_{2} \mathrm{CO}$ : Table 2.

Podocarpusflavone A (2). Yellow power; mp $293{ }^{\circ} \mathrm{C}$; $\operatorname{ESIMS}(\mathrm{m} / \mathrm{z}): 555\left(\mathrm{M}+\mathrm{H}, \mathrm{C}_{31} \mathrm{H}_{22} \mathrm{O}_{10}\right),{ }^{13} \mathrm{C} \mathrm{NMR}\left(\mathrm{CD}_{3}\right)_{2} \mathrm{CO}$ : Table 1.

Agathisflavone (3). Yellow power; mp $310-311^{\circ} \mathrm{C}$. The identification was performed by comparison of MS and NMR spectral data with literature data. ${ }^{8}$

4,4'-Dihydroxy-2'-methoxy-chalcone (4). Yellow crystals; mp 195-8 ${ }^{\circ} \mathrm{C}$; ${ }^{1} \mathrm{H}$ NMR (300 MHz, $\left.\mathrm{CD}_{3} \mathrm{OD}\right) \delta$ : 6.41 (dd, $J 8.3$ and 1.7, H-5'), 6.81 (d, $J$ 8.4, H-3/H-5), 7.40 (d, $J$ 15.7, H- $\alpha$ ), 7.49 (d, $J$ 8.4, H-2/H-6), 7.59 (d, $J$ 15.7, $\mathrm{H}-\beta) ;{ }^{13} \mathrm{C}$ NMR (75 MHz, CD $\left.\mathrm{OD}\right) \delta: 56.1\left(\mathrm{OCH}_{3}\right)$, 100.4 (C-3'), 109.2 (C-6'), 116.9 (C-3/C-5), 117.2 (C- $\alpha)$, 121.6 (C-1'), 128.0 (C-1), 131.3 (C-2/C-6), 133.7 (C-5'), 144.1 (C- $\beta$ ), 161.2 (C-4), 162.5 (C-2'), 164.9 (C-4'), 193.1 (C- $\beta$ '); UV (MeOH) $\lambda_{\max } / \mathrm{nm}: 264,349 ;\left(\mathrm{AlCl}_{3}\right) 265,349$.

(-)-Syringaresinol (5). Identified by comparison of MS and NMR data and literature data. ${ }^{15}[\alpha]_{\mathrm{D}}-25.0^{\circ}(\mathrm{MeOH}, c$ $0.014)$.

\section{Acknowledgments}

The authors are grateful to CNPq (Conselho Nacional de Desenvolvimento Científico e Tecnológico), IMSEAR/CNPq/MCT (Instituto do Milênio do SemiÁrido), CAPES (Coordenação de Aperfeiçoamento de Pessoal de Nível Superior) and to FAPESB (Fundação de Amparo à Pesquisa do Estado da Bahia) for financial support and fellowship. We were indebted to Prof. Dr. Eduardo de J. Oliveira (LTF-UFPB) for ESIMS and to
Prof. Dr. Edilbero R. Silveira (CENAUREMN-UFC) for bidimensional spectra.

\section{References}

1. Joly, A. B.; Botânica - Introdução à Taxonomia Vegetal, Cia Editora Nacional: São Paulo, 1998, pp. 377-380; http:// www.ildis.org/LegumeWeb/6.00, accessed in September 2005.

2. Rezende, C. M.; Corrêa, V. F. S.; Costa, A. V. M.; Castro, B. C. S; Quim. Nova 2004, 27, 414.

3. Saaed, M. A.; Sabir, A. W.; Fitoterapia 2001, 72, 807.

4. Sharma, S. R.; Dwivedi, S. K.; Swarup, D.; J. Ethnopharmacol. 1997, 58, 39.

5. Kuria, K. A. M.; De Coster, S.; Muriuki, G.; Masengo, W.; Kibwage, I.; Hoogmartens, J.; Laekeman, G. M.; J. Ethnopharmacol. 2001, 74, 141; Deharo, E.; Bourdy, G.; Quenedo, C.; Muñoz, V.; Sauvin, M. A.; J. Ethnopharmacol. 2001, 77, 91 .

6. Hikino, H.; Tagushi, T.; Fujimura, H.; Hiramatsu, Y.; Planta Med. 1977, 31, 214; Carvalho, J. C. T.; Teixeira, J. R. M.; Souza, P. J. C.; Bastos, J. K.; Santos Filho, D.; Sarti, S. J.; J. Ethnopharmacol. 1996, 53, 175.

7. Inventário de Plantas Medicinais do Estado da Bahia; Governo do Estado da Bahia (SEPLANTEC), 1ª. ed., 1979, p. 334.

8. Mendes, C. C.; Bahia, M. V.; David, J. M.; David, J. P.; Fitoterapia 2000, 71, 205.

9. Suárez, A. I.; Diaz, B.; Monache, F. D.; Compagnone, R. S.; Fitoterapia 2003, 74, 473.

10. Markham, K. R.; Sheppard, C.; Geiger, H.; Phytochemistry 1987, 26, 3335.

11. Markhan, K. R.; Geiger, H. In The Flavonoids - Advances in Research Since 1986; Harbone, J. B., ed.; Chapman \& Hall: New York, 1994, pp. 441-498.

12. Grynberg, N. F.; Carvalho, M. G.; Velandia, J. R.; Oliveira, M. C.; Moreira, I. C.; Braz-Filho, R.; Echevarria, A.; Braz. J. Med. Biol. Res. 2002, 35, 819.

13. Namikoshi, M.; Nakata, H.; Saitoh, T.; Phytochemistry 1987, 26, 1831.

14. Correia, S. J.; David, J. P.; David, J. M.; Quim. Nova 2003, 26, 36; Mahato, S. B.; Kundu, A. P.; Phytochemistry 1994, 37, 1517.

15. Das, B.; Venkataiah, B.; Kashinatham, A.; Fitoterapia 1999, 70,101 .

Received: June 10, 2005

Published on the web: November 9, 2005 